\title{
Will the California Current lose its nesting Tufted Puffins?
}

\author{
Christopher J Hart ${ }^{\text {Corresp., }}{ }^{1}$, Ryan P Kelly ${ }^{1}$, Scott F Pearson ${ }^{2}$ \\ ${ }^{1}$ School of Marine and Environmental Affairs, University of Washington, Seattle, Washington, United States \\ 2 Washington Department of Fish and Wildlife, Olympia, Washington, United States \\ Corresponding Author: Christopher J Hart \\ Email address: chrish32@uw.edu
}

Tufted Puffin (Fratercula cirrhata) populations have experienced dramatic declines since the mid-19 $9^{\text {th }}$ century along the southern portion of the species range, leading citizen groups to petition the United States Fish and Wildlife Service (USFWS) to list the species as endangered in the contiguous U.S. While there remains no consensus on the mechanisms driving these trends, population decreases in the California Current Large Marine Ecosystem suggest climate-related factors, and in particular the indirect influence of seasurface temperature on puffin prey. Here, we use three species distribution models (SDMs) to evaluate projected shifts in habitat suitable for Tufted Puffin nesting for the year 2050 under two future Intergovernmental Panel on Climate Change (IPCC) emission scenarios. Ensemble model results indicate warming marine and terrestrial temperatures play a key role in the loss of suitable Tufted Puffin nesting conditions in the California Current under both business-as-usual (RCP 8.5) and moderated (RCP 4.5) carbon emission scenarios. Under both emission scenarios, ensemble model results suggest that more than $92 \%$ of currently suitable nesting habitat in the California Current is likely to become unsuitable. Moreover, the models suggest a net loss of greater than $21 \%$ of suitable nesting sites throughout the entire North American range of the Tufted Puffin, regardless of emissionreduction strategies. These model results highlight continued Tufted Puffin declines particularly among southern breeding colonies - and indicate a significant risk of nearterm extirpation in the California Current. 


\section{Will the California Current Lose its Nesting Tufted Puffins?}

2 Christopher J. Hart ${ }^{1}$, Ryan P. Kelly ${ }^{1}$, Scott F. Pearson ${ }^{2}$

$3{ }^{1}$ School of Marine and Environmental Affairs, University of Washington, Seattle, WA, USA

$4{ }^{2}$ Washington Department of Fish and Wildlife, Olympia, WA, USA

5

6 Corresponding Author:

7 Christopher Hart ${ }^{1}$

8

9 Email address: chrish32@uw.edu

10

11

12

13

14

15

16

17

18

19

20

21

22

23

24

25

26

27 


\section{Abstract}

29 Tufted Puffin (Fratercula cirrhata) populations have experienced dramatic declines since the

30 mid-19 $9^{\text {th }}$ century along the southern portion of the species range, leading citizen groups to

31 petition the United States Fish and Wildlife Service (USFWS) to list the species as endangered in

32 the contiguous U.S. While there remains no consensus on the mechanisms driving these trends,

33 population decreases in the California Current Large Marine Ecosystem suggest climate-related

34 factors, and in particular the indirect influence of sea-surface temperature on puffin prey. Here,

35 we use three species distribution models (SDMs) to evaluate projected shifts in habitat suitable

36 for Tufted Puffin nesting for the year 2050 under two future Intergovernmental Panel on Climate

37 Change (IPCC) emission scenarios. Ensemble model results indicate warming marine and

38 terrestrial temperatures play a key role in the loss of suitable Tufted Puffin nesting conditions in

39 the California Current under both business-as-usual (RCP 8.5) and moderated (RCP 4.5) carbon

40 emission scenarios. Under both emission scenarios, ensemble model results suggest that more

41 than $92 \%$ of currently suitable nesting habitat in the California Current is likely to become

42 unsuitable. Moreover, the models suggest a net loss of greater than $21 \%$ of suitable nesting sites

43 throughout the entire North American range of the Tufted Puffin, regardless of emission-

44 reduction strategies. These model results highlight continued Tufted Puffin declines -

45 particularly among southern breeding colonies — and indicate a significant risk of near-term

46 extirpation in the California Current. 


\section{$\underline{\text { Introduction }}$}

$50 \quad$ Worldwide, species are facing increasing challenges associated with rising sea and air

51 surface temperatures (Thomas et al., 2004). Warming climates have resulted in distribution and

52 community abundance changes in species range across multiple taxa (Parmesan \& Yohe, 2003),

53 changes to ecological responses including phenological anomalies correlating to warming

54 seasonal temperatures (Walther et al., 2002) and changes in habitat quality and distribution

55 (Klausmeyer \& Shaw, 2009). Foden et al. (2013) found that $83 \%$ of birds, $66 \%$ of amphibians

56 and $70 \%$ of corals that were identified as highly vulnerable to the impacts of climate change are

57 not currently considered threatened with extinction on the IUCN Red List of Threatened Species,

58 indicating that species' vulnerabilities are likely to be much greater than conservation status

59 alone would suggest.

60 In recent years in the United States, the United States Fish and Wildlife Service

61 (USFWS) and the National Marine Fisheries Service (NMFS) have received several petitions to

62 list species under the Endangered Species Act based on the impacts of climate change (Siegel,

63 K., Cummings, B. 2005; Wolf, S., Cummings, B., Siegel, K., 2008). However, the link between

64 climate change and risk to a species can be difficult to assess. One approach to examining these

65 linkages is to model the interaction between climate and suitable habitat for a given species,

66 given what is already known about the relationship between the species and its habitat. This

67 approach has become an integral component of conservation planning in a world of changing

68 environments (Hagen \& Hodges, 2006; Richardson \& Whittaker, 2010). Ultimately,

69 understanding these linkages can help inform conservation assessments and species and

70 ecosystem management strategies (Carnaval \& Moritz, 2008; Ponce-Reyes et al., 2017), for 
71 example, by estimating the likelihood of losing (or gaining) particular suitable habitats of interest

72 under future climate conditions.

73

74 Tufted Puffins as a Pertinent Example

The Tufted Puffin (Fratercula cirrhata) is an iconic species that is experiencing dramatic

population declines across the southern portion of its geographic range (Piatt \& Kitaysky, 2002).

77 While Tufted Puffin populations in the Alaska Current have remained relatively stable (but see

Goyert et al., 2017), populations in the California Current large marine ecosystem (area of the

eastern Pacific Ocean spanning nearly 3,000 km from southern British Columbia, Canada to Baja

California, Mexico) have declined by approximately $90 \%$ relative to early $20^{\text {th }}$ century estimates,

81 and are currently declining 9\% annually (Hanson \& Wiles, 2015). The number of occupied

82 breeding colony sites in Washington State has declined by $60 \%$ relative to the $1886-1977$

83 average, and 45\% relative to the 1978-1984 average (Hanson \& Wiles, 2015). Range

84 contractions at the southern edge of the Tufted Puffin's habitat in both the eastern and western

85 Pacific Ocean have led to preliminary conservation measures. The Washington Department of

86 Fish and Wildlife has listed the Tufted Puffin as endangered at the state level in 2015 with

87 Japan's Ministry of the Environment listed the species as endangered in 1993 (Osa \& Watanuki,

88 2002; Hanson \& Wiles, 2015; WAC 232-12-014, 2016).

\section{Tufted Puffin Biology and Ecology}

Tufted Puffins are seabirds belonging to the family Alcidae and nest in colonies located

92 on both sides of the North Pacific, ranging in North America from the Channel Islands in

93 southern California $\left(34^{\circ} \mathrm{N}\right)$ to coastal northern Alaska $\left(68^{\circ} \mathrm{N}\right)$ (Piatt \& Kitaysky, 2002) and in 
94 Asia from Hokkaido, Japan $\left(43^{\circ} \mathrm{N}\right)$ through the Kamchatka Peninsula $\left(63^{\circ} \mathrm{N}\right)$ (Hanson \& Wiles,

95 2015). They are central-place foragers during the nesting season, when they dig burrows or use

96 crevices for nesting on nearshore rocks, islands and sea stacks (Piatt \& Kitaysky, 2002). During

97 the nesting season, puffins exhibit large foraging radii around their colonies (up to $40 \mathrm{~km}$, e.g.,

98 Menza et al. (2016) Figure 12) and are able to carry more than twenty fish at a time while flying

99 back to the colony to feed their chicks (Piatt \& Kitaysky, 2002; Hanson \& Wiles, 2015). While

100 little is known about the wintering distribution and ecology of Tufted Puffins, summer (May-

101 September) breeding colonies are well documented and provide the most useful biological data

102 for conservation management (Piatt \& Kitaysky, 2002). Extensive breeding colony surveys

103 dating back to the early $20^{\text {th }}$ century allow us to examine any potential link between climate and

104 species range extent.

105 Tufted Puffins are subject to multiple well-documented ecological stressors—such as

106 increasing eagle predation, habitat degradation, declining prey availability, and fishing net

107 entanglement (Baird, 1991; Degange, et al., 1991; Ricca, et al., 2008)—but several mechanisms

108 associated with temperature stress may be important in driving puffin declines along their

109 southern range boundary. Gjerdrum et al. (2003) found dramatically reduced growth rates and

110 fledging success (development of fledgling wings and muscles for flight) in years with high sea

111 surface temperature (SST) anomalies. Other researchers cite the nutritional demands of puffin

112 chicks and the prey availability and preferences correlating with fledgling success (Hipfner et al.,

113 2007), suggesting a mechanism for the negative effects of high sea surface temperature on puffin

114 chicks. These and other studies point to a link between temperature and demographic trends in

115 the Tufted Puffin and help identify this species as a candidate for distribution modeling. 
116 Modeling outputs may help expose proposed interactions between high ocean temperatures, prey

117 distribution in the water column and puffin breeding success.

118 As a result of these potential threats and documented population declines, the USFWS

119 was petitioned to list the California Current population of the Tufted Puffin (Fratercula cirrhata)

120 as endangered under the Endangered Species Act (ESA) (Sewell, 2014). In order to respond to

121 this petition, the USFWS is currently examining Tufted Puffin status and trends, evaluating

122 threats to its survival, the adequacy of existing regulatory mechanisms to conserve the species,

123 the loss of its habitat, and other relevant factors. Given that climate-specifically, increasing sea-

124 surface temperatures - may be a particularly important factor influencing puffin population

125 dynamics and ultimately reducing puffin breeding range, and given the vast geographic extent of

126 puffin nesting sites ( $34^{\circ}$ of latitude and roughly $70^{\circ}$ of longitude in North America) and

127 historical data on the occupancy of these sites, the Tufted Puffin is an excellent candidate for

128 species distribution modeling.

\section{Species Distribution Models in Conservation Planning}

130 Species distribution models (SDMs) are a powerful way to examine how climate

131 variables relate to species geographic distribution and the distribution of suitable habitat (Guisan

132 \& Zimmermann, 2000; Guisan \& Thullier, 2005). By associating species occurrence with

133 climate variables, these models can 1) test for associations in space and time between putative

134 environmental drivers and changes in species range and 2) project changes in suitable habitat

135 under future climate change scenarios (Bellard et al., 2012). SDMs use a variety of underlying

136 statistical models to capture the relationship between habitat and climate and create detailed

137 outputs highly useful for wildlife management (Carvalho et al., 2011; Guisan et al., 2013). 
138 Recent Endangered Species Act listing decisions and management plans have drawn on SDM

139 results to provide critical spatial and temporal conservation information. For example, climate

140 envelope models were used to develop spatially explicit conservation strategies that account for

141 climate change, notably in the case of the North America Wolverine (Gulo gulo), where the

142 models were the basis of an ESA listing (81 FR 71670, 2016).

143 Here we use 50 years of species nesting habitat distribution information — ranging from

144 the Bering Sea to California - to map Tufted Puffin nesting habitat. We use this colony

145 occupancy data to model the relationship between nesting habitat and current environmental

146 conditions to project future suitable breeding sites in the same geographic range. We present

147 these results as an example of how this information can be used in both regulatory (e.g.,

148 Endangered Species Act listing decisions) and conservation planning contexts.

\section{$\underline{\text { Materials and Methods }}$}

\section{Environmental Data}

152 Environmental data for the current period, which we define here as the years 1950-2000,

153 was downloaded from WorldClim, a set of global climate layers derived from interpolation of

154 monthly climate observations (Hijmans et al., 2005, last accessed January 2017). After removing

155 WorldClim bioclimatic variables displaying high collinearity, we also considered factors relevant

156 to Tufted Puffin breeding phenology including isolating seasons during which puffins breed

157 (spring and summer) and including environmental variables relevant to their prey species such as

158 temperature. These processes resulted in our selection of six environmental variables for

159 analysis: annual temperature range (ATR), mean diurnal temperature range (MDR), mean

160 temperature of the warmest quarter (MTWQ), annual precipitation (AP), precipitation of the 
161 warmest quarter (PWQ) and distance-to-ocean (DIST), a variable we created to help models

162 discern suitable nesting habitat as occurring only in rocky, coastal habitats within meters of the

163 sea, a biological requirement of puffins (Piatt \& Kitaysky, 2002); (see Supplemental Table 1 for

164 measurements and units). Each variable for the current period was scaled to a 5 arcmin grid cell

165 size (ca $10 \mathrm{~km} \times 10 \mathrm{~km}$ ). After scaling, all environmental variables within the relevant

166 geographic range were cropped to only include locations within 200 kilometers of the ocean.

167 While this cropping distance includes land not physically suitable for obligate coastal and island

168 breeders, it is important for creating larger environmental variable gradients during model

169 construction (Van Horn, 2002).

170 The same 6 environmental variables above were averaged over the period of 1910-1950

171 to construct a 'past' climate regime used to project past Tufted Puffin range. Past climate

172 variables were selected using gridded climate data obtained from monthly observations from the

173 Climate Research Unit CRU TS v. 4.01 dataset (Harris et al., 2014 (crudata.uea.ac.uk), last

174 accessed March 2017). Past environmental data was similarly scaled down to the same 5 arcmin 175 grid cell size as the current data.

176 Future Climate

177 We selected emissions scenarios Radiative Concentration Pathways (RCP) 4.5 and 8.5 as

178 defined by the IPCC $5^{\text {th }}$ Assessment Report (IPCC, 2014) as future environmental projections

179 against which to forecast changes in Tufted Puffin breeding distribution. Downscaled model

180 output for environmental variables for both future RCP scenarios were averaged across the

181 following general circulation models: Hadley Centre's HadGEM2-AO (Collins et al., 2011),

182 NOAA’s GFDL-CM3 (Griffies et al., 2011), NASA’s GISS-E2-R (Nazarenko et al., 2015),

183 Institut Pierre-Simon Laplace's IPSL-CM5A-LR (Dufresne, et al., 2013), Beijing Climate 
184 Center's BCC-CSM1-1 (Xin et al., 2013), Bjerknes Centre's NorESM1-M (Bentsen et al., 2013),

185 National Center for Atmospheric Research's CCSM4 (Gent, P.R, et al., 2011) and the Max

186 Planck Institute's MPI-ESM-LR (Giorgetta, et al., 2013), all for the year 2050 (average of 2041-

187 2060) (Hijmans et al., 2005, last accessed January 2017). Utilizing the average of eight

188 prominent climate model outputs helps incorporate variance in potential future climate

189 projections within our model. The 2050 timeframe and these emissions scenarios (roughly

190 speaking, a moderate-reduction scenario and business-as-usual scenario with no emission

191 reductions) were selected as the most relevant to the conservation decisions presently

192 surrounding the Tufted Puffin (IPCC, 2014).

193

194 Species Data Species distribution data was obtained courtesy of USFWS, Washington Department of

196 Fish and Wildlife and Environment and Climate Change Canada, and were derived from

197 expansive U.S. and Canada breeding colony surveys conducted by groups including USFWS,

198 Washington Department of Fish and Wildlife, Alaska Department of Fish and Game,

199 Environment and Climate Change Canada, California Department of Fish and Wildlife, and

200 others (Speich \& Wall, 1989; Hodum et al., see Supplemental File.; World Seabird Union

201 (https://seabirds.net, last accessed March 2017); BCMCA

202 (http://bcmca.ca/datafeatures/eco_birds_tuftedpuffincolonies/), 2017, last accessed May 2017), 203 see supplemental online materials). Count data consisted of estimates of numbers of breeding 204 individuals present at known nesting colonies and the spatial coordinates of those observations.

205 Biological data for the 'current' period of climate data (see Supplemental Table 2) represents the 206 most recent survey observation of known nesting sites from 1950-2009. While the climatological 
207 data runs until the year 2000, biological data from up to 2009 was included to incorporate recent

208 detailed state-wide surveys in both Oregon and Washington, information critical to examining

209 trends across the puffin's southern range. We converted count data to presence/absence values,

210 given the nature of our analysis, which asked whether breeding habitat was likely to be suitable

211 ( $\geq 1$ nesting birds) or not (0) under future conditions. Some observations were adjusted

212 geographically up to one grid cell $(\mathrm{ca} 10 \mathrm{~km})$ to fall within gridded terrestrial environmental

213 variables. Observations further than $15 \mathrm{~km}$ from terrestrial grids (e.g., remote islands) were

214 removed from the analysis. The environmental variables described above were selected to model

215 potential interactions between climate conditions and puffin range during the breeding season.

216 Given the low proportion of absence-to-presence observations for Tufted Puffin surveys

217 and potential bias in survey locations, we added pseudo-absence (PA) observations (i.e.,

218 generated absence observations existing within the range of the SDM) to all models. SDMs using

219 both presence and absence have been shown to perform more accurately than models relying on

220 presence-only observations (Elith et al., 2006, Barbet-Massin et al., 2012). PA generation

221 methodology is also important in both model predictive accuracy and avoiding model over-

222 fitting (Barbet-Massin, Thuiller, \& Jiguet, 2010, Barbet-Massin et al., 2012). Adapting these

223 recommendations in Barbet-Massin et al. (2012), 1000 PAs were randomly generated twice

224 across the SDM a minimum of 30km from any presence or true absence point.

\section{Model Parameterization}

Because Tufted Puffins rely heavily on both terrestrial and marine environments for

227 reproduction, we initially tested the correlation between sea-surface temperature and air-

228 temperature data across puffin colony observations. SST data for this comparison comprised an

229 average of mean monthly temperature for June, July and August, months aligning with Tufted 
230 Puffin breeding season obtained from the Hadley Centre, UK (Rayner et al., 2003

231 (metoffice.gov.uk/hadobs) last accessed March 2017) and the corresponding air temperature

232 readings (MTWQ) (Hijmans et al., 2005). Both sets of environmental variables were scaled to a

2335 arcmin grid cell size and represented means from the years 1950-2000. A high correlation

234 coefficient $(\mathrm{r}=0.96)$ allowed us to use air temperature - which is available in higher spatial

235 resolution - rather than SST in the final analysis. This strong relationship between air- and sea-

236 surface temperature has also been documented across several other marine and aquatic species

237 distribution studies (Stefan \& Preud'homme, 1993; Domisch et al., 2013). Additionally, within R

238 software (R Core Team, 2013), a principal component analysis (PCA) (Pearson, 1901) was

239 performed to compare variance in environmental variables between areas of collapsed colonies

240 (absence) and occupied colonies during the current period. This technique has been shown to

241 help identify differences in environmental niches of species occurrence data (eg. Broennimann et

242 al., 2012; Peña-Gómez et al., 2014); here, we use it to create an index of environmental variables

243 to identify likely drivers of Tufted Puffin declines after accounting for the covariances among

244 variables.

245 Species Distribution Modeling

246 Model Algorithms

247 SDMs were constructed with the R package BIOMOD2 (BIOdiversity MODelling)

248 (Thuiller et al., 2009; R Core Team, 2013). All SDMs were constructed for a spatial range larger

249 than the current estimated U.S. Tufted Puffin distribution $\left(180^{\circ} \mathrm{W}\right.$ to $120^{\circ} \mathrm{W}$ longitude and $33^{\circ} \mathrm{N}$

250 to $69^{\circ} \mathrm{N}$ ). Using a larger extent both increases the range of environmental gradients available for

251 model construction and introduces novel climates useful for projecting potential migration

252 (Thuiller et al., 2004; Fitzpatrick \& Hargrove, 2009; Domisch et al., 2013). Models were also 
253 examined under a subset of all biological and environmental data from $126^{\circ} \mathrm{W}$ to $120^{\circ} \mathrm{W}$ and $25432^{\circ} \mathrm{N}$ to $48.5^{\circ} \mathrm{N}$. This portion of the analysis is intended to account for the spatial variance of 255 puffin distribution and examine the temperature-habitat relationship in the California Current 256 large marine ecosystem exclusively - the portion of the range that has experienced the greatest 257 decline and has been petitioned for listing under the US Endangered Species Act. To help acknowledge and estimate uncertainty, 3 different models using different statistical approaches were selected from the BIOMOD framework; generalized linear models (GLM) (McCullagh \& Nelder 1989), generalized boosting models (GBM, also referred to as boosted regression trees) (Ridgeway, 1999) and random forests (RF) (Breiman, 2001). The GLM models used a logit link between the response variable mean and combination of explanatory variables (Guisan, Edwards, \& Hastie, 2002) (i.e., logistic regression). GBMs incorporate regression and machine-learning techniques through boosting many decision-tree models to increase model performance (Elith et al., 2008). Decision models recursively partition sets of explanitory and outcome variables in a stagewise manner until subsets of data are explained by trees of bifurcating decisions (Elith et al., 2008). Boosting then sequentially fits decision trees to training data, selecting the trees that best fit the data (Elith et al., 2008). Finally, RF represents a machine-learning technique creating classification trees similar to those in GBMs, but instead uses random bootstrap samples of data and explanatory variables upon the construction of each 271 tree (Breiman, 2001). The significant differences in statistical and machine learning approaches across GLM, 273 GBM and RF algorithms provides variance across which to test sensitivity between models as 274 well as estimations of model uncertainty (Marmion et al., 2009; Rodríguez-Castañeda et al., 275 2012). Additionally, using models with relatively more ensemble (GBM and RF) and 
276 parsimonious (GLM) approaches to habitat selection as well as utilizing both parametric (GLM)

277 and non-parametric (RF) techniques provides robust analysis of environmental drivers of range

278 change (Marmion et al., 2009) and led to the selection of these three model algorithms.

279

280

281

282

\section{Model Calibration}

Having generated two variants of the dataset by generating distinct pseudo-absences, we then constructed twenty models for each algorithm (GLM, GBM, RF), for each dataset variant, for a total of 120 models. All models then utilized past environmental data as well as both future emission scenarios to project both past and future puffin range changes. Each model variant performed a random $70: 30$ split of the biological data using $70 \%$ for model calibration and $30 \%$ for model evaluation. This technique addresses spatial autocorrelation and is frequently utilized when faced with dependent biological sampling (surveying of species around only areas of known occurrence) (Araújo et al., 2005). Model selection and calibration parameters were kept constant between past and current models to maintain consistency and repeatability. For all models across all algorithms, the default model construction options and parameters of the BIOMOD package were utilized (Thuiller et al., 2009).

\section{Hindcasting}

Hindcast models were created to examine the past relationship between temperature and patterns of puffin colony occupancy. Hindcasts can increase confidence in future projections and help shed light on ecological interactions over time (Raxworthy et al., 2003; Labay et al., 2011). These 'hindcast' models use current puffin distribution projections and the past environmental data detailed above to project past puffin colony distribution. A limited amount of historical survey data along the California Current, especially in southern Oregon and California, makes 
299 scoring the hindcast projections against past survey data difficult for this analysis. However,

300 examining past model projections at specific known historical locations (such those in Hanson \&

301 Wiles, 2015) in a past, cooler climate helps interpret the influence of a warming climate in the

302 future (Labay et al., 2011).

303 Ensemble Modeling and Evaluation

304 The area under the receiver operating characteristic curve (AUC) and the True Skill

305 Statistic (TSS) were the two model metrics used to evaluate model performance. AUC maps

306 sensitivity rate (true positive) against (1-specificity) values (= false-positive rate) and is a

307 popular metric for species distribution model evaluations because it evaluates across all

308 thresholds of probability conversion to binary presence or absence (Fielding \& Bell, 1997; Guo

309 et al., 2015). Higher AUC scores represent better model performance, with AUC scores between

310 0.7-0.8 classified as 'fair', 0.8-0.9 as 'good' and 0.9-1.0 as 'excellent'(Guo et al., 2015). TSS

311 scores display (sensitivity + specificity -1$)$ with sensitivity quantifying omission errors and

312 specificity quantifying commission errors (Allouche et al., 2006; Guo et al., 2015; Shabani et al.,

313 2016). TSS scores of zero or less indicate model performance no better than random and scores

314 of 1.0 indicating perfect performance. Both scores were emphasized in this analysis to provide

315 strong measures of ordinal model performance and to predict accuracy in threshold-dependent

316 conservation planning (Allouche et al., 2006; Shabani et al., 2016).

317 Ensemble models were created using weighted averages of TSS scores both within and

318 across algorithms while AUC scores were not used in constructing ensemble models but served

319 as another evaluation metric. This technique captures uncertainty stemming from random

320 sampling of the dataset as well as variance across modeling techniques (Gallardo \& Aldridge,

321 2013), thereby providing the user with a robust sense of model fit and sensitivity to particular 
322 parameters. TSS scores below 0.7 were excluded from the ensemble to remove influence from

323 poor predictive models (Araújo et al., 2011). A proportional weight decay was used averaging

324 model weights, resulting in weights proportional to TSS evaluation scores. Additionally, binary

325 conversions, which maximized model TSS performance, were used in some range-change

326 analyses. Range-change analyses were performed allowing future migration to potential suitable

327 future habitat as well as with no potential migration. Ensemble binary thresholds and their

328 impact on projections are noted below.

\section{$\underline{\text { Results }}$}

331

332

333

334

335

336

337

338

339

340

341

\section{Variable Contribution}

343 Response Plots

\section{Model Performance}

Models from all three algorithms, and especially the ensemble model, scored very high in both model performance metrics (Table 1). GLM, GBM and RF algorithms displayed mean TSS scores and standard deviations of $0.842 \pm 0.020,0.898 \pm 0.017$ and $0.905 \pm 0.017$, respectively. Similarly, GLM, GBM and RF mean AUC scores were very high, indicating good model accuracy (Table 1). Techniques utilizing machine learning methods (RF \& GBM) consistently displayed the highest performance by both AUC and TSS scores (Table 1), perhaps due to these machine-learning (GBM \& RF) models relying on boosting and ensemble learning, respectively, compared to a single regression model approach within GLM algorithms. Despite the different statistical and learning approaches of the selected modeling approaches, TSS and AUC scores were high across all techniques and displayed low variance (Table 1).

\section{Response Plots}


that temperature variables ATR and MTWQ are strongly associated with Tufted Puffin breeding

346 habitat (Figure 1, 2). Importantly, MTWQ displayed a thermal maximum of suitable nesting

347 habitat (i.e., a threshold) around $15^{\circ} \mathrm{C}$, and the MTWQ variable also displayed the most

348 consensus across model members among all selected variables (Figure 1). This result highlights

349 consensus among GLM ensemble members surrounding the $15^{\circ} \mathrm{C}$ threshold. ATR and MTWQ

350 are related to extreme summer temperatures and consensus among GLM ensemble members

351 across these variable response plots is consistent with the hypothesis that summer temperature

352 anomalies influence Tufted Puffin colonies.

353 Conversely, MDR and PWQ were not effective in predicting suitable habitat among all

354 models. In fact, the probability of Tufted Puffin occurrence remains high across the range of

355 MDR and PWQ values indicating that these variables are not helpful in predicting puffin

356 occupancy. GLM models do show a response to increased annual precipitation (AP) values, but

357 there remains a lack of consensus among model members around a particular response cutoff.

358 Principal Component Analysis

359 Principal component analysis provided further support to the hypothesis identifying

360 summer temperature as a primary driver of variance in Tufted Puffin breeding habitat (Figure 2).

361 PCA components $1(51 \%)$ and $2(27 \%)$ together explained $78 \%$ of the variability in the data.

362 Component 2, with a strong loading of MTWQ of -0.732 and MDR loading of -0.497 , indicates

363 that MTWQ and MDR explain the difference between presence and absence points as evidenced

364 by the separation of the $95 \%$ confidence ellipse along this component (Figure 2). The other four

365 variables loaded more strongly onto principal component 1 which does not help separate

366 presence and absence points. This result combined with the MTWQ response curves (Figure 2) 
367 indicate the importance of MTWQ in predicting what habitat is suitable for Tufted Puffins

368 (Figure 1, 2).

369 Range Forecasts

370 North American Projections - 2050

371 After binary transformation of the future probabilistic projection maps, ensemble models,

372 again representative of the weighted mean of all model algorithms and variants, project a range

373 loss of approximately $22 \%$ of currently occupied range under RCP 4.5 and a range loss of

374 approximately $26 \%$ under RCP 8.5 by 2050 (Table 1). GLM models projected the greatest

375 percent habitat loss across North America under both emission scenarios (Table 1). There was

376 uniform agreement across ensemble algorithms in projecting habitat loss, even with the

377 possibility of colonizing new habitat, with variability among algorithms as to the magnitude of

378 that loss (Table 1). Spatially, losses were uniformly projected along the California Current up to

379 southeastern Alaska (Figure 3), although ensemble projections suggested continued suitability of

380 the Aleutian Islands under both emission scenarios (Figure 3). Ensemble model results also

381 reflected agreement on the opportunity for northward range expansion (Figure 3). Both the

382 projected southern range contraction and northward range expansion are further consistent with

383 the hypothesized relationship between puffin habitat and temperature.

384 California Current - 2050

385 Analysis of the California Current region within the overall ensemble models shows near

386 complete loss of suitable habitat between emission scenarios with both RCP 4.5 and 8.5 (Figure

387 4), although the individual component models showed variable amounts of habitat loss. GLM

388 models projected the most dramatic loss along the California Current with a predicted loss of

389 greater than $96 \%$ of suitable habitat under both scenarios $(\mathrm{SD}=14.61 \%$ for projections under 
$390 \mathrm{RCP} 4.5, \mathrm{SD}=12.96 \%$ for projections under RCP 8.5) (Table 1). GLM models also projected no

391 habitat as likely to become newly habitable in the California Current under either emission

392 scenario. Both GBM and RF models predicted less range change with GBM models projecting a

393 mean loss of approximately $23 \%$ across algorithm variants and RF models projecting a mean loss

394 of approximately $27 \%$ across algorithm variants under RCP $8.5(\mathrm{SD}=20.27 \%, \mathrm{SD}=26.80 \%$,

395 respectively). Under both RCP 4.5 and 8.5, ensemble projections display complete loss of likely

396 suitable habitat in Oregon and virtually complete loss in California (Figure 4). GBM and RF

397 models projected small portions of northwestern Washington would become slightly more likely

398 than not to become environmentally habitable by 2050 under both emission scenarios, though

399 those locations may not exhibit other puffin habitat requirements.

$400 \underline{\text { Hindcast }}$

401 As stated above, limitations on biological survey for the Tufted Puffin make

402 interpretation of hindcast results difficult, though past projections further supported the

403 hypothesis of higher temperature limiting suitable nesting habitat. See supplementary material

404 for further discussion and presentation of hindcast model results.

405

406

\section{$\underline{\text { Discussion }}$}

407

Ensemble models uniformly support summer temperature as a predictor of Tufted Puffin

408 breeding habitat. High model evaluation metrics (Table 1) coupled with strong correlations

409 between temperature variables and Tufted Puffin range change (Figures 1, 2) provide confidence

410 that projected warmer summer temperatures are likely to be associated with the loss of greater

411 than $92 \%$ of Tufted Puffin breeding habitat in the California Current under the examined

412 emission scenarios (Figure 4). North America-wide, ensemble models project an overall loss 
413 across model algorithms and variants of approximately $22 \%$ and approximately $26 \%$ of suitable

414 habitat, respectively, under moderate emission reductions and business as usual carbon emissions

415 by 2050 (Table 1). Figure 3 highlights that most nesting habitat will be lost along the southern

416 portion of current Tufted Puffin range as well as the opportunity for northward range expansion.

Analysis examining the percent of suitable range change by 2050 highlights large

418 variance across all three model algorithms (Table 1). Variance can be attributable in part due to

419 the differences in modeling techniques across algorithms described above and variance in initial

420 estimation of suitable habitat. Additionally, ensemble projections show little variance in the

421 projected range loss under RCP 4.5 versus RCP 8.5 in the California Current (Table 1, Figure 4).

422 Both ensemble models project minimal suitable habitat remaining along the California Current,

423 therefore under the hypothesized relationship between temperature and suitable habitat, there is

424 little left to become unsuitable with increased warming (Figure 4). Another factor which may

425 contribute to the lack of variance in projected habitat loss, range-wide, under different RCP

426 scenarios in the California Current is the relatively short time frame of 2050 projections.

427 Divergence in the temperature projections of RCPs 4.5 and 8.5 are amplified after 2050 and there

428 is less divergence in temperature in the short term (IPCC, 2014).

429

Important to the interpretation of ensemble projections is the binary transformation of

430 model outputs into suitable and unsuitable categories. For range change analyses, projections of

431 unsuitable habitat represent a weighted average of $<50 \%$ probability of suitability, a cutoff

432 defined by ensemble calibration. In some cases we observed a majority of ensemble members

433 projecting a particular cell as marginally suitable while a minority of members strongly project

434 that cell as unsuitable. The subsequent result is unsuitable habitat despite being marginally

435 suitable in some models. This process of binary transformation can then reflect an aggregate of 
436 probabilistic scores instead of the average of a binary projection. Binary transformations are thus

437 a useful tool to discuss and represent how changes in climate may affect the likelihood of

438 suitable breeding conditions throughout Tufted Puffin range, but are necessarily imprecise in that

439 they mask underlying variability. Additionally, many sites in the ensemble projections (Figure 4)

440 become unsuitable after binary transformations while falling in to the $27 \%-44 \%$ probability bin.

441 Though these are projected as likely to become environmentally unsuitable, the represent

442 marginally suitable environmental habitat and further research may help determine the suitability

443 of other requisite habitat conditions at these sites to provide a broader picture of nesting habitat

444 suitability at these locations.

445 Examining the variance among model results and the spatial variance in projections is

446 integral to the interpretation of model results from a conservation perspective (Guisan et al.,

447 2013; Porfirio et al., 2014). Tufted Puffins are a relatively rare species in the southern portion of

448 their range, are hard to survey, and occupy small areas of land (Hanson \& Wiles, 2015). These

449 biological factors contribute to the difficulty of surveying (and therefore modeling) puffins and

450 can increase variance among model algorithms, making ensemble models more valuable for

451 interpretation of results (Segurado \& Araújo, 2004; Hernandez et al., 2006). However, here we

452 use colony occupancy information rather than counts. Preliminary occupancy analysis suggest

453 that colony occupancy can be assessed with a high probability with a single relatively rapid visit

454 by boat even to a very small colony with few birds (Pearson et al., see Supplemental File). Thus,

455 our colony occupancy approach likely reflects actual changes in colony occupancy throughout

456 the range. In addition, trends were consistent across algorithms in depicting significant losses of

457 suitability for habitat across the California Current (specifically California and Oregon), British 
458 Columbia and eastern Alaska (Figure 3). All algorithms also projected the opportunity for

459 northward range expansion in the face of accelerating northern latitude warming (Figure 3).

460 If suitable habitat expands northward as projected by our ensemble models, biological

461 and ecological factors unrelated to climate such as eagle predation, requisite nesting substrate,

462 etc., are predicted to continue and likely to influence the probability of colonization (Hipfner et

463 al., 2012; Hanson \& Wiles, 2015). Because colonization is uncertain, we depict in Figure 5 the

464 loss of currently suitable habitat in the California Current without the possibility of new

465 colonization throughout the extent $-\mathrm{a}$ worst case scenario but an important component of

466 analysis when examining the threat of climate change. Variance among models as evidenced in

467 Table 1 along the California Current failed to result in more than a handful of consensus areas of

468 suitability (Figure 4). Ensemble models did depict some areas of marginally suitable habitat

469 along central California (Figure 4). This result was likely influenced by a few outlying colonies

470 such as the one in the Farallon Islands, California. These outlying colonies persist in opposition

471 to the trends seen in other colonies throughout the southern portion of puffin range. Further

472 examination of the mechanisms driving puffin declines in their southern range may shed light on

473 either the viability of these outlying suitable habitat projections as potential climate refugia or

474 other mechanisms supporting these outlying colonies.

475 The discussed hard to model specific requirements of puffin nesting habitat and other

476 ecological population drivers make fine scale colony-by-colony analysis of extirpation risk

477 difficult. Additionally, analysis of regional trends in puffin success can serve to guide research

478 examining the specific causal mechanisms driving documented declines which would aid in

479 further analysis of colony-by-colony extirpation risk. Importantly, all models and especially

480 ensemble results support the trend of southern range contraction associated with warm summer 
481 temperatures (Figures 1, 2, 3, 4). Additionally, while limitations on historical survey data make

482 interpretation of hindcasts difficult, preliminary hindcasting resulted in expansion across the

483 southern portion of current puffin habitat (see supplemental file). This result is further consistent

484 with the hypothesized relationship between high temperature and puffin success.

485 Our results are especially salient in light of the ongoing U.S. Fish and Wildlife Service's

486 analysis of puffin status following Natural Resources Defense Council's petition to list the

487 California Current population as endangered. When responding to the petition to list the puffin,

488 the Service can list the species throughout its range or can list a distinct population segment

489 (DPS) such as the breeding population south of the Canadian border or that in the California

490 Current. While determining which segments comprise a DPS as outlined by the ESA requires

491 more analysis, our results provide the spatial information to inform the threat that both of these

492 breeding range segments or "populations" will likely face. Based on our modeling, all potential

493 distinct populations segments from British Columbia, south, face a significant chance of near

494 extirpation or very significant habitat loss under a wide range of climate projections by 2050.

495 Conservation planning for species can greatly benefit from defining the portion(s) of their

496 range representing habitat critical to their survival (Hagen \& Hodges, 2006). This designation is

497 essential for conservation planning both under the ESA as well as Canadian Species at Risk Act,

498 in which it is required for listed species, as well as for more localized conservation efforts

499 (Taylor et al., 2005). Figures 3 and 4 highlights areas where Tufted Puffins are currently at the

500 highest risk of colony loss (low habitat suitability). Many puffin nesting sites are already

501 managed by the US Fish and Wildlife Service refuge system and many of these sites are also

502 designated as "wilderness" (Speich and Wahl 1989 and US Fish and Wildlife Service, n.d).

503 Habitat projections made for the year 2050 permit analysis of critical habitat in terms of species 
504 survival as well as proposed conservation efficacy (Suckling \& Taylor, 2006; Stein et al., 2013).

505 Land acquisition has proven to be an effective strategy for the management of endangered

506 species and is a strategy that has been utilized for the Tufted Puffin (Lawler et al., 2003; WDFW,

507 2016) and could be used in the future. With limited resources to conserve species at the federal

508 level, ranking the conservation priorities and temporally analyzing threats can allow for prudent

509 investment in conservation lands (Lawler et al., 2003). Nesting colony sites throughout the Gulf

510 of Alaska are projected to remain suitable and results indicate the Aleutian Islands are the most

511 likely habitat to both continue to support large populations of Tufted Puffins as well as

512 potentially becoming suitable as new breeding sites (Figure 3). As these results suggest, we can

513 use this information to predict areas of future Tufted Puffin habitat to help outline areas for long-

514 term conservation action while also mapping areas where long-term conservation efforts may

515 prove ineffective. Such proactive conservation steps often result in greater conservation

516 outcomes and are critical for species struggling to adapt to changing climates (Morrison et al., 517 2011).

518

519 Mechanisms Driving Decline

$520 \quad$ Using the results reflected in Figures 3 and 4, wildlife managers can continue to explore

521 the causal mechanisms driving the discussed Tufted Puffin population declines and range

522 contraction. Currently numerous pathways are proposed to help determine puffin breeding

523 success and adult survival such as prey availability, SST, predation and habitat degradation

524 (Morrison et al., 2011; Hanson \& Wiles, 2015). While many prey species do not show significant

525 population trends (MacCall, 1996), our results can provide spatial details to explore a potential

526 mechanistic explanation, vertical prey distribution (Gjerdrum et al., 2003). Exact measurements 
527 are unknown but based on body size, Tufted Puffins exhibit the deepest maximum forage depths

528 across alcids, at approximately 110 meters, but typically forage at 60 meters or less (Piatt \&

529 Kitaysky 2002). Tufted Puffins also forage much further offshore than most other alcids and in

530 deeper waters along continental shelf breaks (Ostrand et al., 1998 \& Menza et al., 2016).

531 Foraging in deeper waters may leave Tufted Puffins susceptible to downward movement of prey

532 species in the water column during high temperatures (Ostrand et al., 1998; Gjerdrum et al.,

533 2003). Further research around these biological and ecological factors can be combined with our

534 model results to further explore the mechanisms behind the temperature-range relationship for

535 Tufted Puffins (Ostrand et al., 1998; Piatt \& Kitaysky, 2002).

536 In addition to uncovering causal mechanisms, current conservation efforts are beginning

537 to examine diverging population patterns among related birds, Rhinoceros Auklets (Cerorhinca

538 monocerata), Cassin's Auklets (Ptychoramphus aleuticus) as well as Tufted Puffins along the

539 California Current (Grémillet \& Boulinier, 2009; Morrison et al., 2011). While these three alcids

540 fill similar ecological roles, recent years have seen dramatic population swings varying among

541 species (e.g. El-Niño of 1997-98) (Morrison et al., 2011). Cassin's Auklets have displayed

542 similar ecological sensitivity to changing environmental conditions and have experienced recent

543 large scale mortality events as recently as 2015 (Sydeman et al., 2006; Wolf et al., 2010; Hanson

$544 \&$ Wiles, 2015). Physiological and ecological differences between these related seabird species

545 such as forage radius, foraging depth, and diet composition may provide insights into the

546 mechanisms responsible for these differences in population trends among species (Sydeman et

547 al., 2001; Wolf et al., 2009; Wolf et al., 2010; Morrison et al., 2011). For example, using SDMs

548 to model multiple species may provide insights into the relative influence of climate change on

549 populations trends (Johnson et al., 2017). 
552 Our analysis shows a strong negative correlation between warm summer temperatures

553 and Tufted Puffin nesting range, particularly along the California Current. Construction of SDMs

554 utilizing two different emissions scenarios for the year 2050 show southern range contraction

555 and suggest a high risk of Tufted Puffin extirpation in the California Current large marine

556 ecosystem. Ensemble projections support preliminary analyses suggesting that temperature is

557 driving the current puffin population declines and colony loss. SDM model results can provide

558 valuable input for conservation decision processes. Specifically, our work provides the

559 foundation for evaluating the threat of climate change and increased summer temperatures on

560 Tufted Puffin breeding range.

561

562

563

564

565

566

567

568

569

570

571

572 
576 We would like to thank Shawn Stephenson of the United States Fish and Wildlife

577 Service, Laurie Wilson of Environment and Climate Change Canada and Robert Kaler of the

578 Alaska Department of Fish and Game for their help in compiling Tufted Puffin survey data. We 579 would also like to thank Eric Ward of the National Oceanic and Atmospheric Administration for 580 his help in model parameterization.

581

582

583

584

585

586

587

588

589

590

591

592

593

594

595 
599

600

601

602

603

604

605

606

607

608

609

610

611

612

613

614

615

616

617

618

619

620

621

622

623

624

625

626

627

628

629

630

631

632

633

634

635

636

637

638
Allouche, O., Tsoar, A., \& Kadmon, R. (2006). Assessing the accuracy of species distribution models: Prevalence, kappa and the true skill statistic (TSS). Journal of Applied Ecology, 43(6), 1223-1232.

Araújo, M. B., Pearson, R. G., Thuiller, W., \& Erhard, M. (2005). Validation of species-climate impact models under climate change. Global Change Biology, 11(9), 1504-1513.

Araújo, M. B., Alagador, D., Cabeza, M., Nogués-Bravo, D., \& Thuiller, W. (2011). Climate change threatens European conservation areas. Ecology Letters, 14(5), 484-492.

Baird, P. (1991). Optimal foraging and intraspecific competition in the Tufted Puffin. The Condor, 93(3), 503-515.

Barbet-Massin, M., Thuiller, W., \& Jiguet, F. (2010). How much do we overestimate future local extinction rates when restricting the range of occurrence data in climate suitability models? Ecography, 33(5), 878-886.

Barbet-Massin, M., Jiguet, F., Albert, C. H. \& Thuiller, W. (2012), Selecting pseudo-absences for species distribution models: how, where and how many? Methods in Ecology and Evolution, 3: 327-338.

Bellard, C., Bertelsmeier, C., Leadley, P., Thuiller, W., \& Courchamp, F. (2012). Impacts of climate change on the future of biodiversity. Ecology Letters 15(4) 365-377.

Bentsen, M., Bethke, I., Debernard, J. B., Iversen, T., Kirkevåg, A., Seland, Ø.,... Kristjánsson, J. E.: The Norwegian Earth System Model, NorESM1-M - Part 1: Description and basic evaluation of the physical climate, Geoscientific Model Development (6) 687-720.

Breiman, L. (2001). Random forests. Machine Learning, 45(1), 5-32.

British Columbia Marine Conservation Analysis (n.d) Maps, Data \& Reports. Available at: https://bcmca.ca/datafeatures/eco_birds_tuftedpuffincolonies/ (accessed May 2017).

Broennimann, O., Fitzpatrick, M. C., Pearman, P. B., Petitpierre, B., Pellissier, L., Yoccoz, N. G., ... Guisan, A. (2012). Measuring ecological niche overlap from occurrence and spatial environmental data. Global Ecology and Biogeography, 21(4), 481-497.

Carnaval, A. C., \& Moritz, C. (2008). Historical climate modelling predicts patterns of current biodiversity in the Brazilian Atlantic forest. Journal of Biogeography, 35(7), 1187-1201.

Carvalho, S. B., Brito, J. C., Crespo, E. G., Watts, M. E., \& Possingham, H. P. (2011). Conservation planning under climate change: Toward accounting for uncertainty in predicted species distributions to increase confidence in conservation investments in space and time. Biological Conservation, 144(7), 2020-2030.

Collins, W. J., Bellouin, N., Doutriaux-Boucher, M., Gedney, N., Halloran, P., Hinton, T., ...Woodward, S. (2011). Development and evaluation of an Earth-System modelHADGEM2. Geoscientific Model Development, 4, 1051-1075.

DeGange, A. R., \& Day, R. H. (1991). Mortality of Seabirds in the Japanese Land-Based Gillnet Fishery for Salmon. The Condor, 93(2), 251-258.

Domisch, S., Araújo, M. B., Bonada, N., Pauls, S. U., Jähnig, S. C., \& Haase, P. (2013). Modelling distribution in European stream macroinvertebrates under future climates. Global Change Biology, 19(3), 752-762. 
639 Dufresne, JL., Foujols, MA., Denvil, S., Caubel, A., Marti, O., Aumont, O., ... Vuichard, N..

640

641

642

643

644

645

646

647

648

649

650

651

652

653

654

655

656

657

658

659

660

661

662

663

664

665

666

667

668

669

670

671

672

673

674

675

676

677

678

679

680

681

682

683

684 (2013). Climate change projections using the IPSL-CM5 earth system model: from CMIP3 to CMIP5. Climate Dynamics, 40(9), 2123-2165.

Elith, J., Graham, C., Anderson, R., Dudík, M., Ferrier, S., Guisan, A., ... Zimmermann, N. (2006). Novel methods improve prediction of species' distributions from occurrence data. Ecography, 29(2), 129-151.

Elith, J., Leathwick, J. R., \& Hastie, T. (2008). A working guide to boosted regression trees. Journal of Animal Ecology 77(4), 802-813.

Fielding, A. H., \& Bell, J. F. (1997). A review of methods for the assessment of prediction errors in conservation presence/absence models. Environmental Conservation, 24(1), 38-49.

Foden, WB, Butchart, SHM, Stuart SN, Vie' J-C, Akcakaya HR, Angulo, A., ... Mace, G. (2013) Identifying the World's Most Climate Change Vulnerable Species: A Systematic Trait-Based Assessment of all Birds, Amphibians and Corals. PLoS ONE 8(6). e65427.

Fitzpatrick, M. C., \& Hargrove, W. W. (2009). The projection of species distribution models and the problem of non-analog climate. Biodiversity and Conservation, 18(8), 2255-2261.

Gallardo, B., \& Aldridge, D. C. (2013). Evaluating the combined threat of climate change and biological invasions on endangered species. Biological Conservation, 160, 225-233.

Gent, P. R., Danabasoglu, G., Donner, L.J., Holland, M.M., Hunke, E.C., Jayne, S.R...Zhang, M. (2011). The Community Climate System Model Version 4. Journal of Climate, 24, 49734991.

Giorgetta, M. A.,Jungclaus, J., Reick, C., Legutke, S., Bader, J., Bottinger, M., ... Stevens, B. (2013), Climate and carbon cycle changes from 1850 to 2100 in MPI-ESM simulations for the Coupled Model Intercomparison Project phase 5. Journal of Advances in Modeling Earth Systems (5), 572-597.

Gjerdrum, C., Vallee, A. M., St. Clair, C. C., Bertram, D. F., Ryder, J. L., \& Blackburn, G. S. (2003). Tufted puffin reproduction reveals ocean climate variability. Proceedings of the National Academy of Sciences, 100(16), 9377-9382.

Goyert, H.F., E.O. Garton, B.A. Drummond, and H.M. Renner. (2017) Density dependence and changes in the carrying capacity of Alaskan seabird populations. Biological Conservation 209:178-187.

Grémillet, D. \& Boulinier, T. (2009). Spatial ecology and conservation of seabirds facing global climate change: a review. Marine Ecology Progress Series, 391, 121-137.

Griffies, S. M., Winton, M., Donner, L. J., Horowitz, L. W., Downes, S. M., Farneti, R., ... Zadeh, N. (2011). The GFDL CM3 coupled climate model: Characteristics of the ocean and sea ice simulations. Journal of Climate, 24(13), 3520-3544.

Guisan, A., \& Zimmermann, N. E. (2000). Predictive habitat distribution models in ecology. Ecological Modeling, 135(2), 147-186.

Guisan, A., Edwards, T., \& Hastie, T. (2002). Generalized linear and generalized additive models in studies of species distributions: setting the scene. Ecological Modelling 157 (2), 89-100.

Guisan, A., \& Thuiller, W. (2005). Predicting species distribution: Offering more than simple habitat models. Ecology Letters 8(9), 993-1009.

Guisan, A., Tingley, R., Baumgartner, J. B., Naujokaitis-Lewis, I., Sutcliffe, P. R., Tulloch, A. I. ,... Buckley, Y. M. (2013). Predicting species distributions for conservation decisions. Ecology Letters, 16(12), 1424-1435.

Guo, C., Lek, S., Ye, S., Li, W., Liu, J., \& Li, Z. (2015). Uncertainty in ensemble modelling of 
685

686

687

688

689

690

691

692

693

694

695

696

697

698

699

700

701

702

703

704

705

706

707

708

709

710

711

712

713

714

715

716

717

718

719

720

721

722

723

724

725

726

727

728

729

large-scale species distribution: Effects from species characteristics and model techniques. Ecological Modelling, 306, 67-75.

Hagen, A. N., \& Hodges, K. E. (2006). Resolving critical habitat designation failures:

Reconciling law, policy, and biology. Conservation Biology 20(2), 399-407.

Hanson, T. \& G. J. Wiles. (2015). Washington state status report for the Tufted Puffin.

Washington Department of Fish and Wildlife, Olympia, Washington. 66 pp.

Harris, I., Jones, P. D., Osborn, T. J., \& Lister, D. H. (2014). Updated high-resolution grids of monthly climatic observations - the CRU TS3.10 Dataset. International Journal of Climatology, 34(3), 623-642.

Hatch, S. A., \& Sanger, G. A. (1992). Puffins as samplers of juvenile forage fish in the Gulf of Alaska. Marine Ecology Progress Series, 80, 1-14.

Hernandez, P. A., Graham, C. H., Master, L. L., \& Albert, D. L. (2006). The effect of sample size and species characteristics on performance of different species distribution modeling methods. Ecography, 29(5), 773-785.

Hijmans, R. J., Cameron, S. E., Parra, J. L., Jones, P. G., \& Jarvis, A. (2005). Very high resolution interpolated climate surfaces for global land areas. International Journal of Climatology, 25(15), 1965-1978.

Hipfner, J. M., Charette, M. R., \& Blackburn, G. S. (2007). Subcolony Variation In Breeding Success In The Tufted Puffin (Fratercula Cirrhata): Association With Foraging Ecology And Implications. The Auk, 124(4), 1149-1157.

Hipfner, J.M., Blight, L.K., Lowe, R.W., Wilhelm, S.I., Robertson, G.J., Barrett, R.T.,... Good, T.P. (2012). Unintended consequences: how the recovery of sea eagle Haliaeetus spp. populations in the northern hemisphere is affecting seabirds. Marine Ornithology 40: 3952.

IPCC, (2014) Climate Change 2014: Synthesis Report. Contribution of Working Groups I, II and III to the Fifth Assessment Report of the Intergovernmental Panel on Climate Change [Core Writing Team, R.K. Pachauri and L.A. Meyer (eds.)]. IPCC, Geneva, Switzerland, 151 pp.

Johnson, C. N., Balmford, A., Brook, B. W., Buettel, J. C., Galetti, M., Guangchun, L., \& Wilmshurst, J. M. (2017). Biodiversity losses and conservation responses in the Anthropocene. Science, 356(6335), 270-275.

Klausmeyer, K.R., \& Shaw, M.R., (2009). Climate change, haaitat loss, protected areas and the climate adaptation potential of Mediterranean ecosystems worldwide. PLoS One 4(7): e6932.

Labay, B., Cohen, A. E., Sissel, B., Hendrickson, D. A., Martin, F. D., \& Sarkar, S. (2011). Assessing historical fish community composition using surveys, historical collection data, and species distribution models. PLoS ONE, 6(9), e25145.

Lawler, J. J., White, D., \& Master, L. L. (2003). Integrating Representation and Vulnerability : Two Approaches for Prioritizing Areas for Conservation. Ecological Applications, 13(6), 1762-1772.

MacCall, A. (1996). Patterns of Low-Frequency Variability In Fish Populations of the California Current. CalCOFI Rep., 37, 100-110.

Marmion, M., Parviainen, M., Luoto, M., Heikkinen, R. K., \& Thuiller, W. (2009). Evaluation of consensus methods in predictive species distribution modelling. Diversity and Distributions, 15(1), 59-69.

McCullagh P. \& Nelder, J. A. (1989) Generalized Linear Models. London: Chapman and Hall. 
730

731

732

733

734

735

736

737

738

739

740

741

742

743

744

745

746

747

748

749

750

751

752

753

754

755

756

757

758

759

760

761

762

763

764

765

766

767

768

769

770

771

772

773

774

775

Menza, C., Leirness, J., White, T., Winship, A., Kinlan, B., Kracker, L.,... Antrim, L. (2016). Predictive Mapping of Seabirds, Pinnipeds and Cetaceans off the Pacific Coast of Washington. NOAA Technical Memorandum NOS NCCOS 210. Silver Spring, MD. 96 pp. Morrison, S. A., Sillett, T. S., Ghalambor, C. K., Fitzpatrick, J. W., Graber, D. M., Bakker, V. J., ... Boyce, W. M. (2011). Proactive Conservation Management of an Island-endemic Bird Species in the Face of Global Change. BioScience, 61(12), 1013-1021.

Nazarenko, L., Schmidt, G. A., Miller, R. L., Tausnev, N., Kelley, M., Ruedy, R., ... Zhang, J. (2015). Future climate change under RCP emission scenarios with GISS ModelE2. Journal of Advances in Modeling Earth Systems, 7(1), 244-267.

Osa, Y., and Y. Watanuki. 2002. Status of seabirds breeding in Hokkaido. Journal of the Yamashina Institute for Ornithology 33:107-141.

Ostrand, W.D., Coyle, K.O., Drew, G.S., Maniscalco, J.M. \& Irons, D.B. (1998). Selection of forage-fish schools by murrelets and Tufted Puffins in Prince William Sound, Alaska. Condor 100: 286-297.

Parmesan, C. and Yohe, G. (2003) A globally coherent fingerprint of climate change impacts across natural systems. Nature 421, 39-42.

Pearson, K. (1901). On lines and planes of closest fit to systems of points in space. Philosophical Magazine Series 6, 2(11), 559-572.

Peña-Gómez, F. T., Guerrero, P. C., Bizama, G., Duarte, M., \& Bustamante, R. O. (2014). Climatic niche conservatism and biogeographical non-equilibrium in Eschscholzia californica (Papaveraceae), an invasive plant in the Chilean Mediterranean Region. PLoS ONE, 9(8), e105025.

Piatt, J. F., \& Anderson, P.J. (1996). Response of Common Murres to the Exxon Valdez oil spill and long-term changes in the Gulf of Alaska marine ecosystem. American Fisheries Society Symposium 18:720-737.

Piatt, J. F., \& Kitaysky, A.S. (2002). Tufted Puffin Fratercula cirrhata. Birds of North America $708: 1-31$.

Piatt J. F., Sydeman, W., \& Wiese, F. (2007) Introduction: a modern role for seabirds as indicators. Marine Ecology Progress Series 352:199- 204.

Ponce-Reyes, R., Plumptre, A. J., Segan, D., Ayebare, S., Fuller, R. A., Possingham, H. P., \& Watson, J. E. M. (2017). Forecasting ecosystem responses to climate change across Africa's Albertine Rift. Biological Conservation, 209, 464-472.

Porfirio, L. L., Harris, R. M. B., Lefroy, E. C., Hugh, S., Gould, S. F., Lee, G., ... Mackey, B. (2014). Improving the use of species distribution models in conservation planning and management under climate change. PLoS ONE, 9(11), e113749.

R Core Team (2013). R: A language and environment for statistical computing. R Foundation for Statistical Computing, Vienna, Austria. URL http://www.R-project.org/.

Raxworthy, C. J., Martinez-Meyer, E., Horning, N., Nussbaum, R. A., Schneider, G. E., OrtegaHuerta, M. A., \& Townsend Peterson, A. (2003). Predicting distributions of known and unknown reptile species in Madagascar. Nature, 426(6968), 837-841.

Rayner, N. A., Parker, D., Horton, E., Folland, C., Alexander, L., Rowell, D., ...Kaplan, A. (2003). Global analyses of sea surface temperature, sea ice, and night marine air temperature since the late nineteenth century. Journal of Geophysical Research, 108(D14), 4407.

Ricca, M. A., Keith Miles, A., \& Anthony, R. G. (2008). Sources of organochlorine contaminants and mercury in seabirds from the Aleutian archipelago of Alaska: Inferences 
776

777

778

779

780

781

782

783

784

785

786

787

788

789

790

791

792

793

794

795

796

797

798

799

800

801

802

803

804

805

806

807

808

809

810

811

812

813

814

815

816

817

818

819

820

821

from spatial and trophic variation. Science of the Total Environment, 406(1-2), 308-323.

Richardson, D. M. \& Whittaker, R. J. (2010). Conservation biogeography - foundations, concepts and challenges. Diversity and Distributions, 16: 313-320.

Ridgeway, G. (1999). The state of boosting. Computing Science and Statistics 31:172-181

Rodríguez-Castañeda, G., Hof, A. R., Jansson, R., \& Harding, L. E. (2012). Predicting the Fate of Biodiversity Using Species' Distribution Models: Enhancing Model Comparability and Repeatability. PLoS ONE, 7(9), e44402.

Segurado, P., \& Araujo, M. B. (2004). An evaluation of methods for modelling species distributions. Journal of Biogeography, 31(10), 1555-1568.

Sewell, Bradford. (2014) Petition to list the contiguous U.S. distinct population segment of Tufted Puffin (Fratercula cirrhata) under the Endangered Species Act. Natural Resources Defence Council, New York, New York. 51 pp.

Shabani, F., Kumar, L., \& Ahmadi, M. (2016). A comparison of absolute performance of different correlative and mechanistic species distribution models in an independent area. Ecology and Evolution, 6(16), 5973-5986.

Siegel, K., Cummings, B. (2005). Petition to list the polar bear (Ursus maritimus) as a threatened species under the Endangered Species Act. Center for Biological Diversity, Tucson, Arizona. 154 pp.

Speich, S. M, \& T. R. Wahl. (1989). Catalog of Washington seabird colonies. U.S. Fish and Wildlife Service Biological Report 88(6), U.S. Fish and Wildlife Service, Washington, D.C., and Minerals Management Service, Los Angeles, California. 510 pp.

Stefan, H. G., \& Preud'homme, E. B. (1993). Stream temperature estimation from air temperature. Journal of the American Water Resources Association, 29(1), 27-45.

Stein, B. A., Staudt, A., Cross, M. S., Dubois, N. S., Enquist, C., Griffis, R., ... Pairis, A. (2013). Preparing for and managing change: Climate adaptation for biodiversity and ecosystems. Frontiers in Ecology and the Environment, 11, 502-510.

Suckling, K., \& Taylor, M. (2006). Critical Habitat and Recovery. In Dale D. Goble, J. Michael Scott, \& Frank W. Davis (eds.), The Endangered Species Act at Thirty, Volume 1: Renewing The Conservation Promise (pp. 75-89). Washington: Island Press, 2006.

Sydeman, W. J., M. M. Hester, J. A. Thayer, F. Gress, P. Martin, \& J. Buffa. (2001). Climate change, reproductive performance and diet composition of marine birds in the southern California Current system, 1969-1997. Progress in Oceanography 49: 309-329.

Sydeman, W. J., Bradley, R., Warzybok, P., Abraham, Jahncke, C., Hyrenbach, K., ... Ohman, M. (2006). Planktivorous auklet (Ptychoramphus aleuticus) responses to ocean climate, 2005: unusual atmospheric blocking? Geophysical Research Letters 33:L22S09.

Taylor, M. F. J., Suckling, K. F., \& Rachlinski, J. J. (2005). The Effectiveness of the Endangered Species Act: A Quantitative Analysis. BioScience, 55(4), 360-367.

Thomas, C., Cameron, A., Green, R., ...Williams, S. (2004). Extinction Risk from climate change. Nature, 427, 145-148.

Thuiller, W., Brotons, L., Araújo, M. B., \& Lavorel, S. (2004). Effects of restricting environmental range of data to project current and future species distributions. Ecography, 27(2), 165-172.

Thuiller, W., Lafourcade, B., Engler, R., \& Araújo, M. B. (2009). BIOMOD - A platform for ensemble forecasting of species distributions. Ecography, 32(3), 369-373.

United States Fish and Wildlife Service. (1996). Policy Regarding the Recognition of Distinct Vertebrate Population Segments under the Endangered Species Act. 61 Fed. Reg. 26:4722- 
822

823

824

825

826

827

828

829

830

831

832

833

834

835

836

837

838

839

840

841

842

843

844

845

846

847

848

849

850

851

852

853

854

855

856

4725.

United States Fish and Wildlife Service. (2007). Washington Islands National Wildlife Refuges, Flattery Rocks, Quillayute Needles, and Copalis National Wildlife Refuges: comprehensive conservation plan and environmental assessment. U.S. Fish and Wildlife Service, Port Angeles, Washington.

United States Fish and Wildlife Service (2016). Endangered and Threatened Wildlife and Plants; Proposed Ruling for the North American Wolverine. 81 Fed. Reg. 201: 71670-71671.

United States Fish and Wildlife Service. (n.d). National Wildlife Refuge System. Available at: https://www.fws.gov/refuges/whm/wilderness.html (accessed March 2017).

Van Horn, B. (2002). Approaches to habitat modelling: the tensions between pattern and process and between specificity and generality. In: Predicting Species Occurrences: Issues of Accuracy and Scale (eds Scott, J.M., Heglund, P.J., Morrison, M.L., Haufler, J.B., Raphael, M.G., Wall, W.A. \& Samson, F.B.). Island Press, Covelo, CA, pp. 63-72.

Walther, G., Post, E., Convey, P., ..., Bairlein, F. (2002). Ecological responses to recent climate change. Nature, 416, 389-395.

Washington Department of Fish and Wildlife. (2016). Wildlife Area Management Planning Framework. Web. Available at: http://wdfw.wa.gov/publications/01810/wdfw01810.pdf (accessed 21 March 2017).

Washington Fish and Wildlife Commission. (2016). WSR 16-11-023 (Order 16-84), § 232-12014.

Wolf, S., Cummings, B., Siegel, K. (2008). Petition to list three seal species under the endangered species act: ringed seal (pusa hispida), bearded seal (erignathus barbatus), and spotted seal (phoca largha). Center for Biological Diversity, Tucson, Arizona. 139 pp.

Wolf, S. G., W. J. Sydeman, J. M. Hipfner, C. L. Abraham, B. R. Tershy, \& D. A. Croll. (2009). Range-wide reproductive consequences of ocean climate variability for the seabird Cassin's Auklet. Ecology 90:742-753.

Wolf, S., Snyder, M., Sydeman, W., Doaks, D. \& Croll, D. (2010). Predicting population consequences of ocean climate change for an ecosystem sentinel, the seabird Cassin's auklet. Global Change Biology, 16, 1923-1935.

World Seabird Union. (n.d.). North Pacific Seabird Data Portal. Web. Available at: $\mathrm{http}$ ://axiom.seabirds.net/maps/js/seabirds.php?app=north_pacific $\# \mathrm{z}=3 \& 1 \mathrm{l}=55.00000,-$ 170.00000 (accessed 28 March 2017).

Xin, X.-G., T.-W. Wu, and J. Zhang. (2013). Introduction of CMIP5 experiments carried out with the climate system models of Beijing Climate Center. Advances Climate Change Research. 4(1), 41-49. 


\section{Table $\mathbf{1}$ (on next page)}

Evaluation metrics and range change analysis.

Evaluation metrics and range change analysis for ensemble model and by model algorithm $(\mathrm{N}=40)$. A) Model area under the receiver operating characteristic curve (AUC) and true skill statistic (TSS) for ensemble model and by algorithm. AUC represents sensitivity rate (true positive) against 1-specificity values (false positive) and TSS represents (sensitivity + specificity - 1). Scores presented are mean plus or minus standard deviation B) Percent of projected change in range by model algorithm. North America-wide and U.S. California Current $\left(32^{\circ} \mathrm{N}-48.5^{\circ} \mathrm{N}\right)$ independent analyses. Both RCP 4.5 (4.5 also shaded light grey) and RCP 8.5 ( 8.5 also shaded darker grey) represented. Scores presented are mean plus or minus standard deviation. 


\begin{tabular}{|c|c|c|c|c|}
\hline & Ensemble & GLM & GBM & $\mathbf{R F}$ \\
\hline \multicolumn{5}{|l|}{ A) Model Evaluation } \\
\hline TSS & .920 & $.842 \pm .020$ & $.898 \pm .017$ & $.905 \pm .017$ \\
\hline AUC & .994 & $.976 \pm .004$ & $.985 \pm .004$ & $.986 \pm .004$ \\
\hline \multicolumn{5}{|l|}{ B) \% Range Change } \\
\hline Species-Wide & -21.80 & $-22.59 \pm 11.69$ & $-13.88 \pm 11.72$ & $-17.99 \pm 20.33$ \\
\hline California Current & -92.68 & $-96.69 \pm 14.61$ & $-16.95 \pm 20.12$ & $-21.26 \pm 26.10$ \\
\hline Species-Wide & -26.14 & $-31.37 \pm 14.70$ & $-14.09 \pm 13.74$ & $-19.23 \pm 23.79$ \\
\hline California Current & -97.56 & $-97.13 \pm 12.96$ & $-22.71 \pm 20.27$ & $-27.26 \pm 26.80$ \\
\hline
\end{tabular}




\section{Figure 1}

GLM model algorithm variable response plots.

Response curves across GLM algorithms for all environmental variables. A) ATR response curves B) MDR response curves C) MTWQ response curves D) AP response curves E) PWQ response curves F) DIST response curves. Each colored line represents one GLM model run $(\mathrm{N}=40)$. Y-axis displays predicted probability of habitat suitability across each variable given other variables are held fixed at their mean value. X-axis displays environmental variable values (see Supplemental Table 1 for specific units). Results display distinct cutoffs between ATR, MTWQ and occurrence probability.
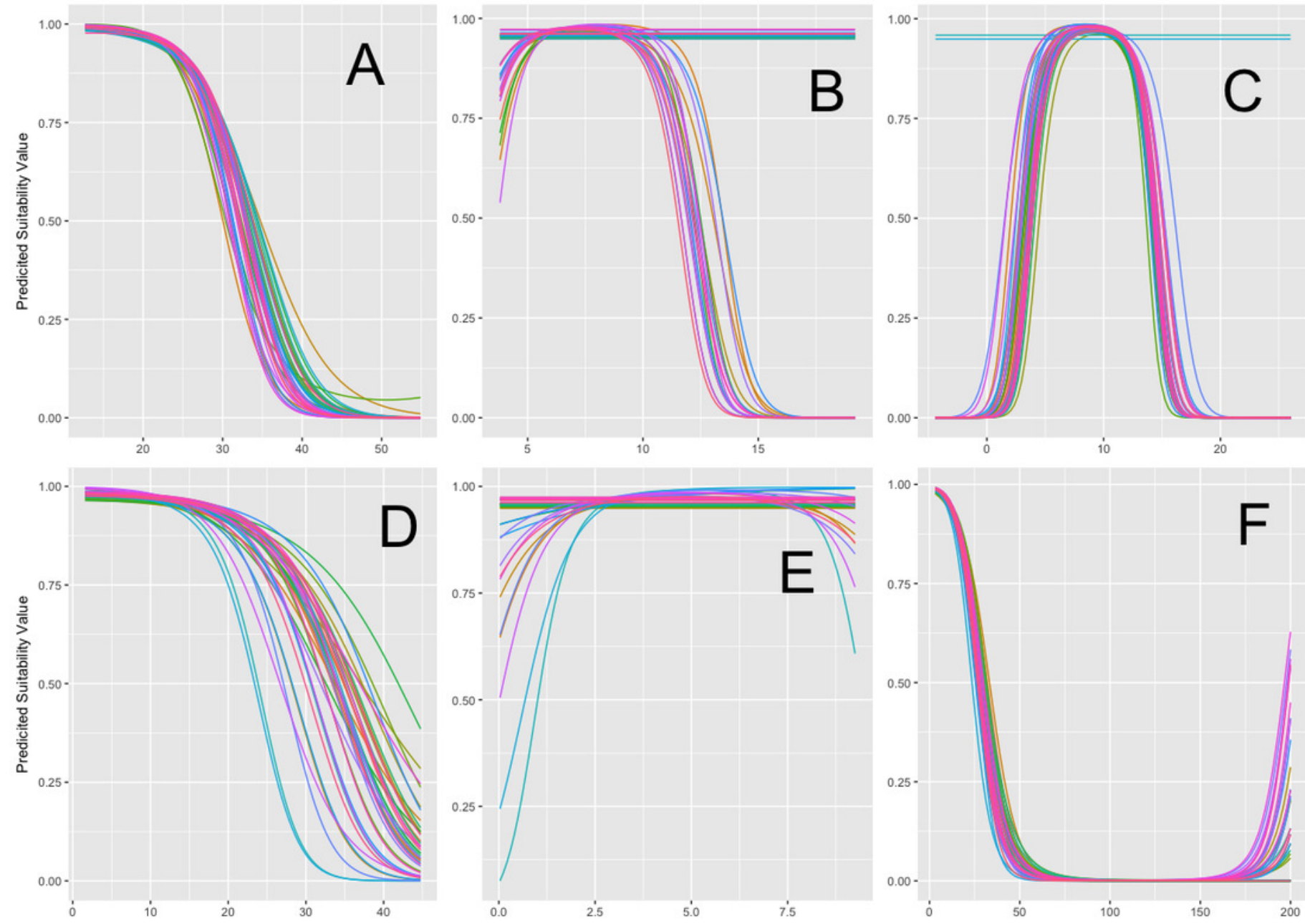
Figure 2

Principal component analysis.

Principal component analysis loadings 1 and 2 (95\% confidence ellipses) for occupied (present) and unoccupied (absent) nesting colonies.

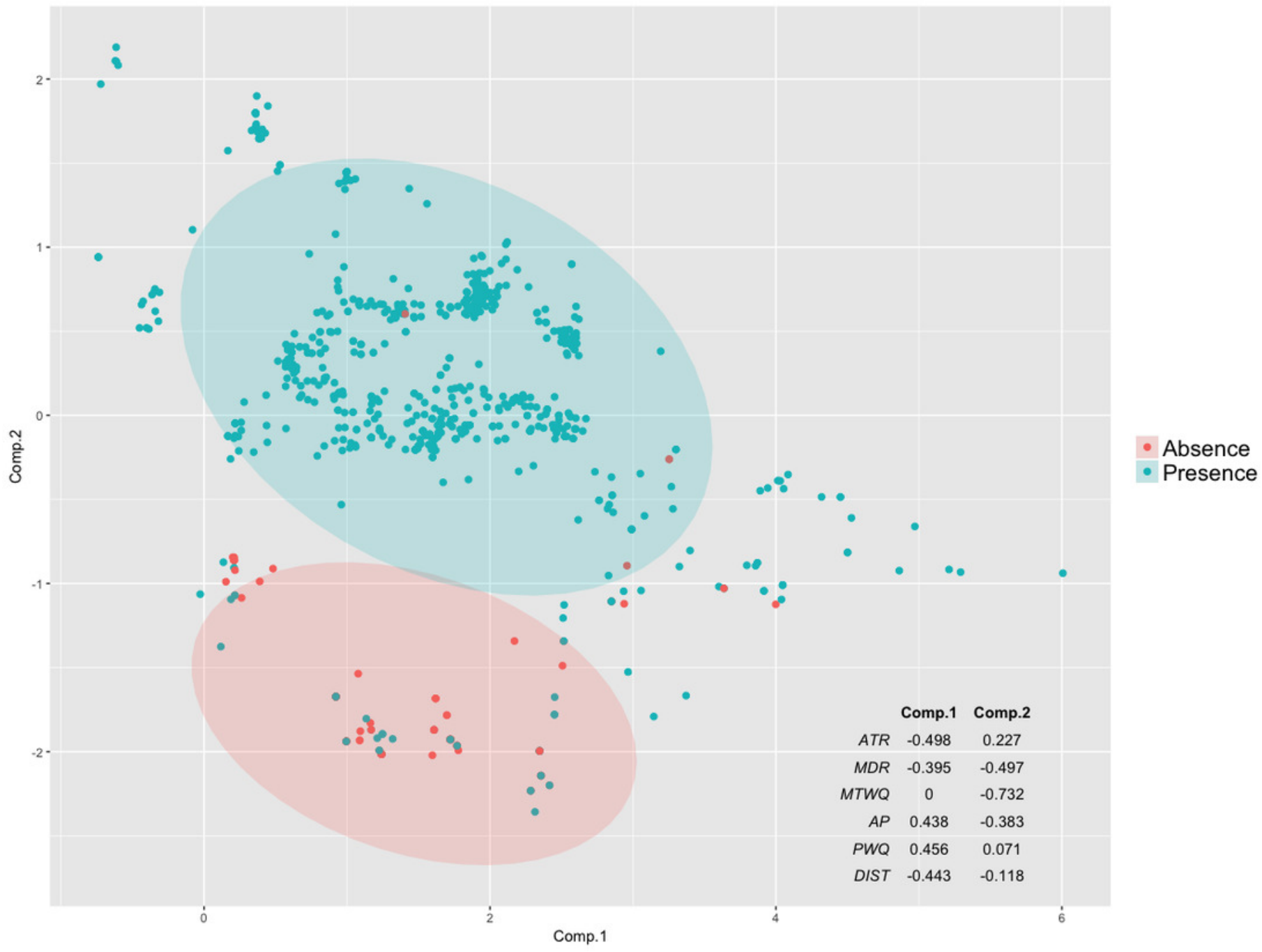


Figure 3

North-America-wide habitat projection maps.

Tufted Puffin breeding habitat range projection maps. Probabilistic maps, color bins display percent probability of grid cell representing suitable habitat. A) Current projections. B) 2050 projections under RCP 4.5. C) 2050 projections under RCP 8.5. Map data (c) 2017 Google.
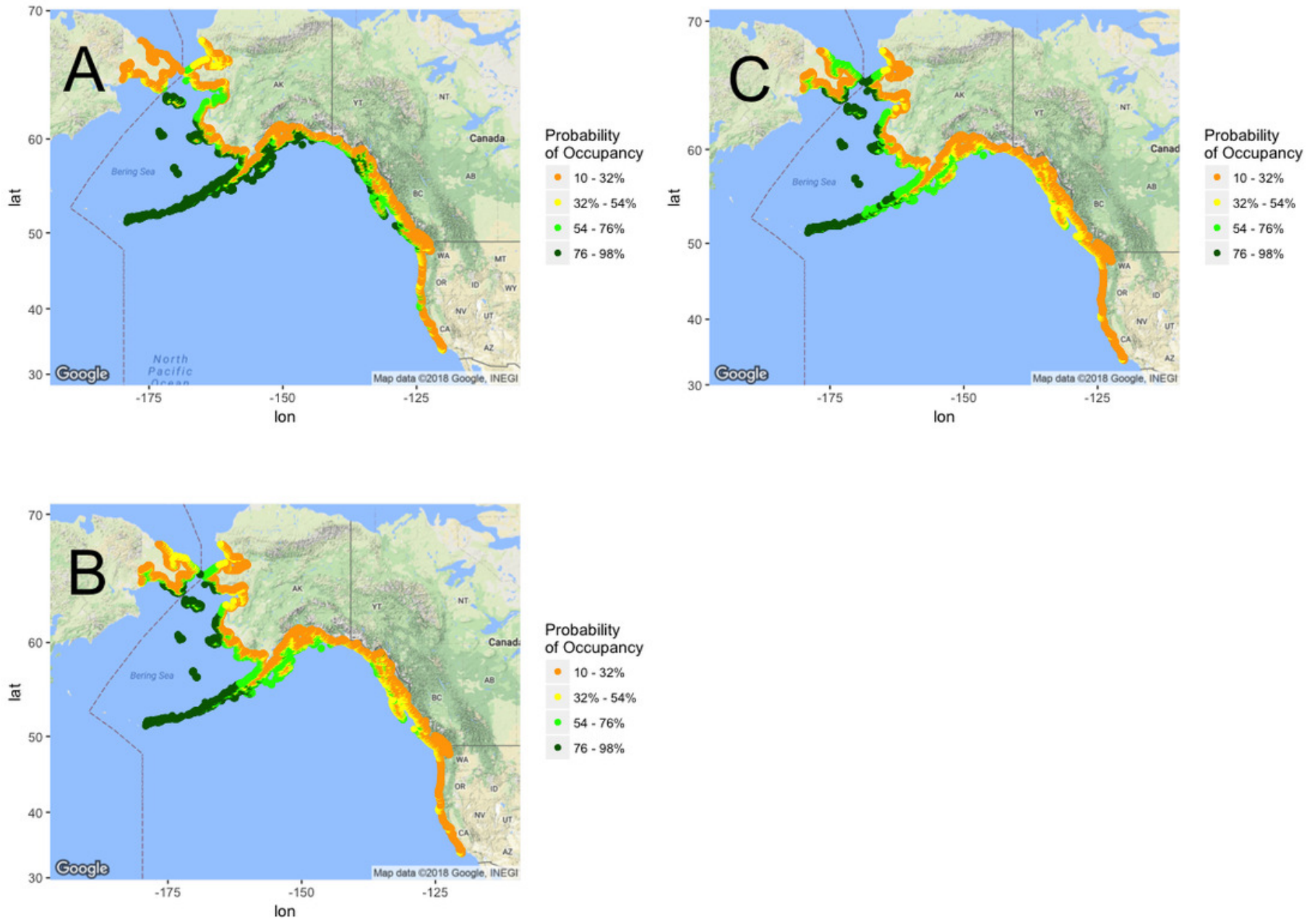


\section{Figure 4}

California Current habitat projection maps.

Tufted Puffin breeding habitat range projection maps exclusive to the California Current ( $32^{\circ} \mathrm{N}-48.5^{\circ} \mathrm{N}$ ). Probabilistic maps, color bins display percent probability of grid cell

representing suitable habitat. A) Current projections. B) 2050 projections under RCP 4.5. C) 2050 projections under RCP 8.5. Note: Probability bin "61-78\%" absent in B and C as projections do not reflect any habitat within that bin. Map tiles @ Stamen Design, underCC BY 3.0. Data (c) OpenStreetMap, underODbL.
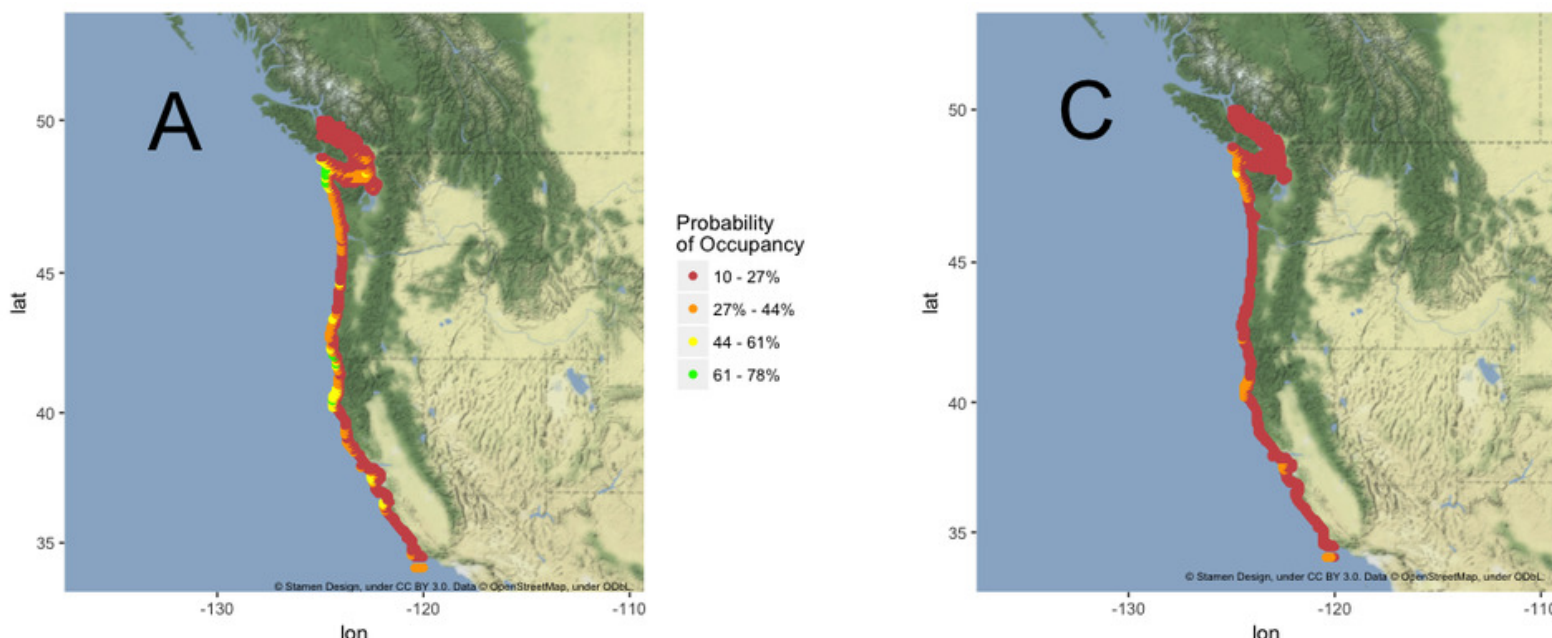

Probability of Occupancy

- $10-27 \%$

$27 \%=44 \%$

$44-61 \%$

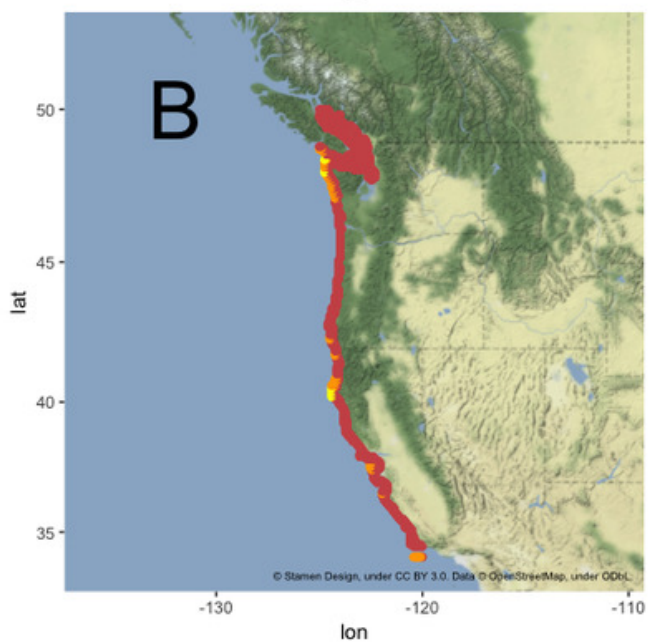

Probability

of Occupancy

- $10-27 \%$

- $27 \%-44 \%$

$44-61 \%$ 


\section{Figure 5}

Histogram of habitat loss in the California Current with no migration.

Histogram displaying the amount of current California Current Extent suitable habitat projected to become unsuitable by 2050 under RCP $8.5(\mathrm{~N}=120)$. Colors represent model algorithms. In this analysis, there is an assumption of no migration or dispersal to potentially suitable new habitat.

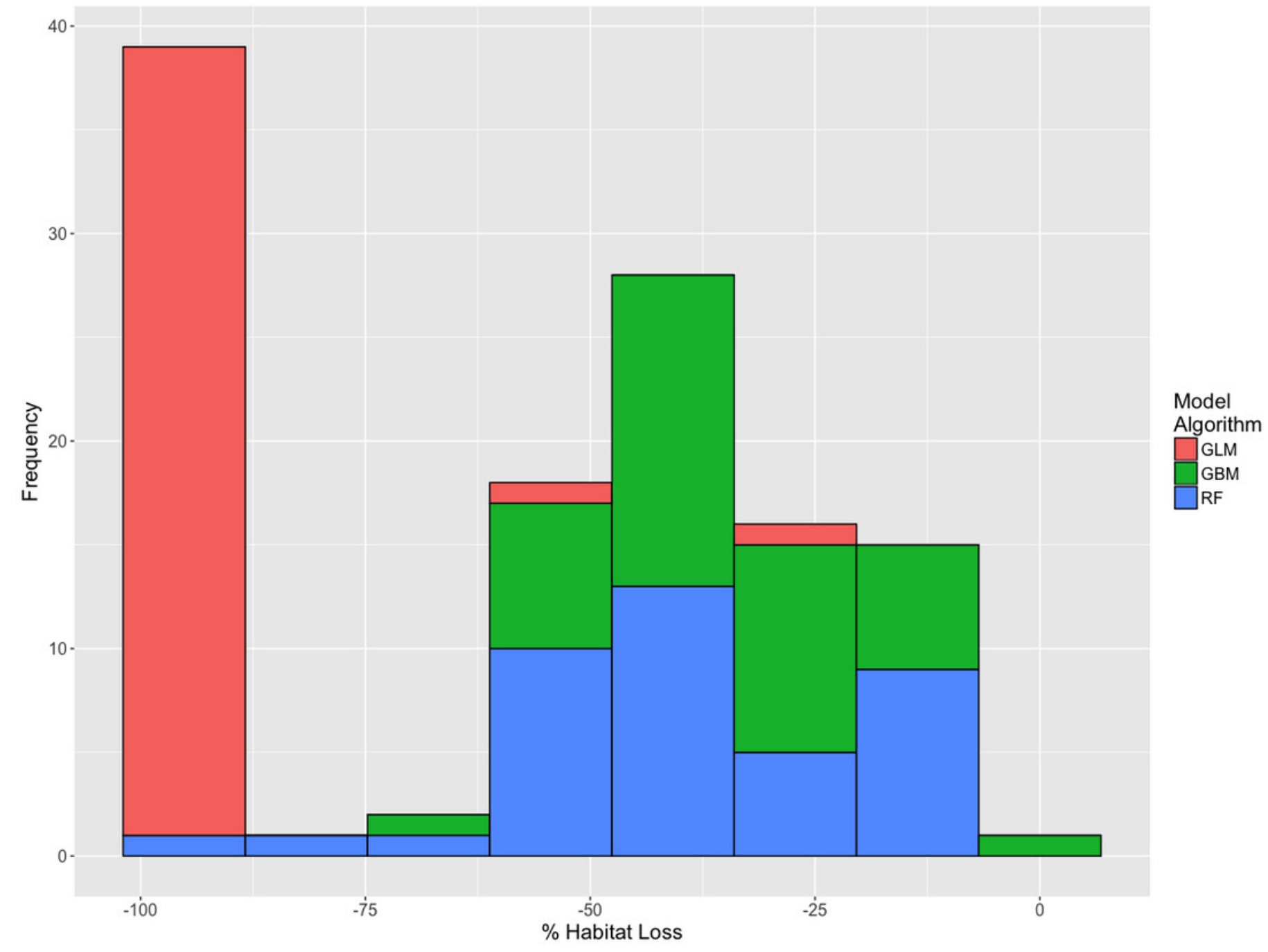

